\title{
Transcending the Digital Divide: Video Use Communication Models for the English Language Learning Classroom
}

\author{
Terrill Reid McLain, MBA (Corresponding Author) \\ Hankuk University of Foreign Studies \\ Assistant Professor, Global Business and Technology \\ HUFS Humanities Building \#408-1 \\ 81 Oedae Ro, Mohyeon-myeon, Cheoin-gu \\ Yongin-si Gyeonggi-do 17035 \\ South Korea \\ E-mail: reidmclain@hufs.ac.kr
}

Received: August 15, 2018 Accepted: August 30, 2018 Published: August 31, 2018

doi:10.5296/ijele.v6i2.13581 URL: https://doi.org/10.5296/ijele.v6i2.13581

\begin{abstract}
With the development of web 2.0 tools, many companies are rushing to meet the demand and create attractive and useful Educational Technology (EdTech) that appeal to instructors to implement in their classes. Many of these tools include video services that are available to everyone with a connected device. ESL Instructors also look for new and engaging activities and techniques to help their students L2 confidence and language practice. Research shows that video is a powerful and useful tool for educators to boost language learning in the classroom. When deciding to implement video in the classroom, it is essential to understand the different attributes that students experience surrounding the consumption, the creation, and interaction with video. To effectively implement video in the English class it is also necessary to understand how videos replicate elements of the communication process to determine what kind of - if any-interaction will take place. Once the attributes are understood, and the communication model is chosen, teachers can select a tool that fits their pedagogical practice and logistical situation. This paper explores the justification and use categories of video in the context of English language learning, introduces the idea of Video Use Communication Models to help instructors choose a tool that will align with their pedagogical goals, and advocate the promotion of video solutions that allow affordable and available access for an English teacher who wants to use video.
\end{abstract}


Keywords: Video, CALL, ESL, Language Learning, EdTech, Classroom, Digital Divide, English, FlipGrid

\section{Background}

The use of video in the classroom can be traced back to the introduction of the movie projector in schools in the early 1900's. The engaging format of film was recognized early on for its value in learning and education. Some of the early experiments for videos in Education was during World War II to train soldiers, this both saved time and helped boost their skills (as cited in Yousef, Chatti, \& Schroeder, 2014, p. 112). As videos made their way to the traditional classroom, they were primarily shown during class-time as there were not affordable options for all students to have at home. Much of the use of video lessons in the classroom was for an alternative way to disseminate information, enhance a lesson visually, or show situations that could not be replicated in regular classes, i.e., videos were used for the consumption of information.

As the technology developed so did the accessibility and affordability of video tools; these changes added the ability for video to be used not only for consumption but for communication. Today video making, video sharing, $\mathrm{V}$ and video chatting are a regular part of daily life. Interacting with video on social media apps such as Snap Chat, Facebook, and Instagram is a common and ordinary activity amongst students in most educational settings (Ripton \& Scott, 2016). Modern devices are equipped with a video camera, microphone, and are ready to connect to the internet. Many students have these devices, and because of this device saturation students are adept at sharing videos with each other. These connected students are motivated and enjoy being social with video with their friends. "Motivation is a key element in the learning process. It is a factor that must be considered and maintained throughout any lesson, and throughout a course or program" (Williams \& Lutes, 2008, p. 6). As Ripton notes: "Every teacher can take advantage of video, even those who are not technologically savvy. Students are using video for social purposes, and teachers should be using it for instructional gain in the classroom, too" (Ripton \& Scott, 2016). ESL/EFL teachers can also access this motivation with video use as it is not only for engagement but for improvement in speaking and other language skills.

\section{Integrating Videos for English Learning}

There are many reasons why the teacher would want to implement videos in the English classroom. It is essential for the use of video to enhance the learning rather than be an extra factor added to lessons so that it becomes a burden to the students. Adding video assignments to lessons and homework is simple because students are connected to their phones and social media "at all possible times" so, there are fewer reasons - or excuses — for not being able to do the work. This translates to a more useful tool for teachers to use. Students who are learning languages also find the implementation of videos beneficial. A 2015 study of a flipped classroom found that students who were able to control playback aspects for videos 
that were assigned as homework, by stopping or replaying videos as many times as necessary, helped them understand the material better (Basal, 2015). For English learners' video use in class ranges from watching target language dialogues to films and newsreels exposing learners to the 'natural' language. They also include video projects and presentations plus the use of video conferencing to allow classrooms to expand outside of the classroom walls. Established tools-YouTube, Vimeo, etc.-allow video use outside the classroom for the practice, production, and creation of language. Newer tools such as FlipGrid allow for enhanced interactive elements for both instructors and students.

When selecting any technology for the classroom, a model called SAMR was developed to assist instructors in adapting their lessons for technology use (developed by Puentedura, 2013a). This model presents a hierarchy of attributes for lessons that use technology. The (S) stands for substitution; this is for activities that use technology as a simple replacement over traditional tools; the same functions of learning happen no matter which device is used. The (A) stands for augmentation; this is for technology that offers a substitution but also an improvement over a "non-tech" tool for the functionality that the traditional tool cannot provide. The M stands for modification; this is where tasks are redesigned for collaborative learning. Finally, (R) stands for redefinition, when the "tech allows for the creation of new tasks, previously inconceivable" (Puentedura, 2013a; Puentedura, 2013b). As an instructor becomes more comfortable with technology they are more likely to adapt to the more complex attributes of $(\mathrm{M})$ and $(\mathrm{R})$, so starting with activities that are simply a substitute (S) or (A) is one way for teachers to begin to use video.

When explicitly implementing video technology in the class, the main ways in which videos are used in the classroom can be distilled into three categories; video consumption, video creation, and video interaction. It is important to distinguish that the attributes are meant to describe video use, and not to other educational technologies or class activities. Knowing which one of these attributes represent the planned video activity will help instructors when applying the SAMR model for integrating technology into their classes and implement their pedagogies.

\subsection{Video Consumption}

All video assignments have consumption elements by default because there are always times where participants watch. For class use, videos are created for the students - as compared to by the students. Consumption methods of video used in the English classroom are a way for learners to practice their language skills with the added benefit of listening practice and to expose learners to native speakers' rhythms and other audible and visual attributes. If used for speaking, the speaking practice happens outside of the video watching activity. Students then process the information internally, so consumption works best when combined with other class elements; a reflection writing, a quiz, and in-class discussion, etc. Because the learning processing is internal, it has the potential for students to become disengaged. As Williams (2008) notes, the consumption of video in the classroom is a passive activity and needs to accompany other activities (Williams \& Lutes, 2008, p. 4). However, research supports introducing video clips into the classroom is valuable when combined with group learning 
activities. Students in these studies showed an improvement in their English-speaking skills (Muslem, Mustafa, \& Usman..., 2017). Videos used inside the classroom may only be a substitution of a lecture or to break up the monotony of a lecture; however, videos can be seen at and consumed at home using available services such as YouTube or Vimeo. As Basal (2015) noted, traditional methods are tied to the classroom time and location whereas implementing flipped (with video) lessons to free up both instructors and students to experience better learning opportunities (Basal, 2015).

\subsection{Video Creation}

Integrating video into the classroom is not limited to the consumption of video but also to the creation of it. Video creation activities are student-centered activities involving inventing and creating what is seen on the video. The activities can range from storytelling, video comments, filmed discussions, video blogs, and more. Most of the use of video creation activities take planning with the result being consumed or used by others. These activities allow students to use their voice and creativity and encourage participation. Sarah DeMaria and Cathi Fuhrman write about a successful project that was implemented for 10th graders in Philadelphia (DeMaria \& Fuhrman, 2011). They were able to transform an English literature lesson on The Adventures of Huckleberry Finn in their classrooms by having students make and produce videos of their interpretation of the novel. They noticed a 5\% improvement on the unit test that accompanies the unit (DeMaria \& Fuhrman, 2011, p. 34). The learning that happens as a result of the collaboration benefits from the positive qualities that accompany collaborative learning (Gan, Menkhoff, \& Smith, 2015; Kumar \& Sharma, 2016; Yang, 2014).

\subsection{Video Interaction}

Video interaction attributes require a back and forth between participants. Both synchronous and asynchronous interaction video assignments can be created for the classroom that can encourage students to interact and speak to each other. Video conferences fit into the interaction section if two-way communication is included. If the video conferencing lesson design does not include students, then it provides the video consumption attribute only. Video conferencing in the ESL classroom was studied in Taiwan found that the students demonstrated similar behaviors as in a regular classroom - shy students not speaking, some students becoming disinterested, etc. (Yu, 2018). So, video chats that allow one-on-one discussion synchronously may provide more speaking interaction than full class lectures using the same tool. However, there are new tools that are allowing video interaction asynchronously that were not possible just a couple of years ago. These new tools allow for group interaction to take place at a location, time and offers playback options preferable to the learner. The ability to take their time and re-record speaking is allowing shy students to have a chance to show their voice and ESL students are showing an increase in their speaking competencies (Bakar, Latiff, \& Hamat, 2013). As of the writing of this paper, a tool called FlipGrid is gaining traction as the tool that allows this amplified asynchronous interaction. This tool provides for activities with a combination of all three video implementation elements; these activities start to place the learning into the hands of the learners and the 
SAMR (2017) integration level to (R).

\section{Video Implementation and the Communication Cycle}

If instructors choose to utilize video, it may help to understand how video relates to the communication process. These models are preliminarily based on standard communication theory models that have evolved. As more educational technology tools are developed that include video, these communication models in relation to video may change, but the idea is to align the desired interaction with the lesson that is planned. Using the communication cycle as a starting point, instructors can model lesson planning to fit the most appropriate model. When looking at how participants/students participate in a video lesson, we divide them into either active roles or passive roles. Passive roles are cognitive processes that are internal-in the case of video, reflect. Sometimes passive learning is warranted and desired because the participation piece happens outside of video use. Alternatively, active roles are external, meaning learners must produce — in the case of video, speak.

\subsection{Standard Linear Model}

This model is a passive role use, see Figure 1. Listening practice and other traditional in-class video use methods. The communication is one direction, the video is the sender, and the participant is the receiver. It is based on the one-way models of communication developed from Shannon and Weaver in 1949 (as cited in Hamilton, 2014, p. 4). This model has been effectively used in the past in classrooms see (Blonskytè, 2014).

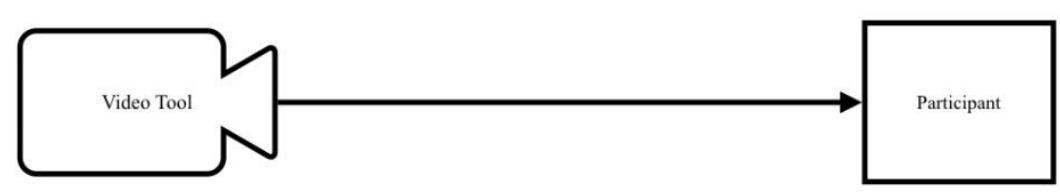

Figure 1. Standard Linear Model

\subsection{Synchronous Interactive Model}

This model is an active role use, see Figure 2. This model facilitates an in-person conversation face-to-face interaction between two participants using video at the same time. The communication happens in both directions. What differentiates this model compared to the linear model is that both sides are practicing by participating in real time. It most represents aspects of the circular model developed by Schramm in 1955 (as cited in Hamilton, 2014, p. 4; referencing Schramm, 1971) or transactional model introduced by Barnlund in 1910 (as cited in Hamilton, 2014, p. 4). It also is dependent on scheduling as the participants need to access the video tool at the same time for it to work. 


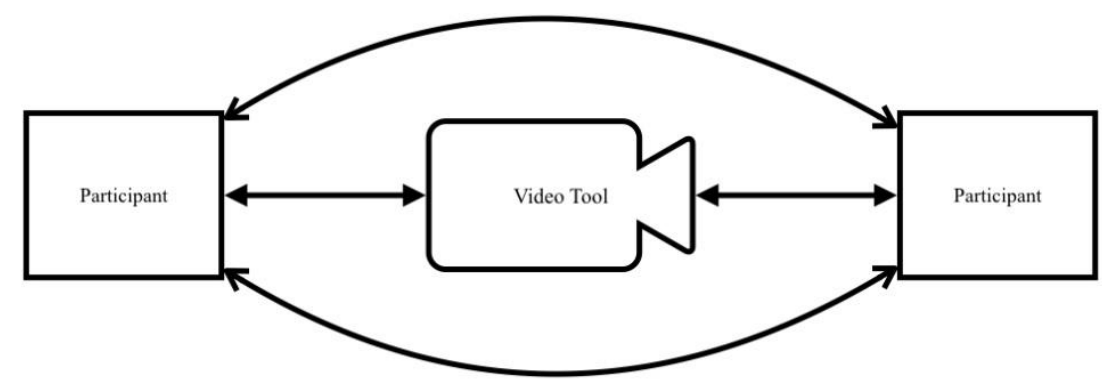

Figure 2. Synchronous Interactive Model

\subsection{Synchronous Group Interactive Model}

This model is an augmentation of the Synchronous Interactive Model and can be both active and a passive role use, see Figure 3. What separates this particular video use style is that more than two people are interacting; it is the video conference call or online class meeting with three or more participants. Depending on the class needs, this model can present a hybrid of interactive and linear. This model is the closest representation to an actual classroom situation. With this model, some students who partake in the communication interaction and some who will not. Some may not listen to or receive communication from others, or there may be lurkers who replicate the liner model. If a video implementation only has one speaker and the audience does not participate - even if the participants are also being viewed on the video screen-it falls under the linear model. The appearance of the Synchronous Group Interactive Model may appear orderly, interactive, and organized, but the communication may not be that different than a standard classroom.

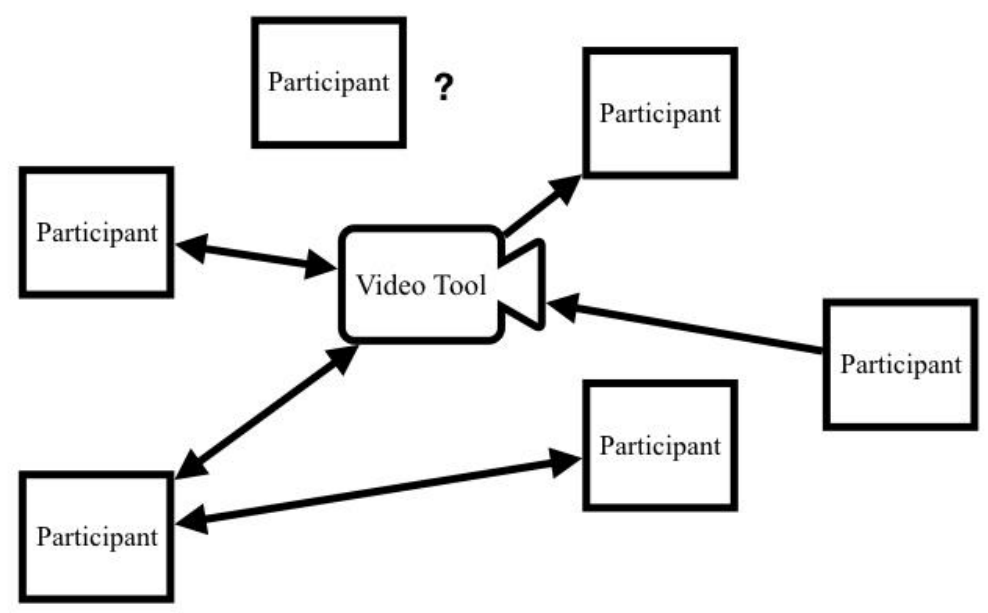

Communication Reality

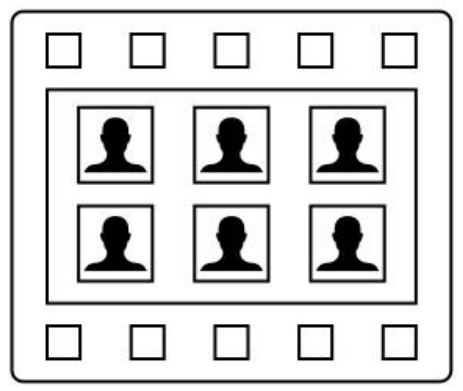

Appearance

Figure 3. Synchronous Group Interactive Model 


\section{Macrothink}

\subsection{Asynchronous Linear Model}

This model is a passive role use., see Figure 4 This model is used when the video used accessed and viewed by learners at different times and is not reliant upon a schedule. This allows students to have control of when they access the video and give them opportunities to replay the video as needed. Video assignments consumed as homework assignments outside of class allows instructors time during class to implement more interactive activities in the classroom. This model is also used when an instructor makes asynchronous video comments and feedback on students work rather than written comments. As with other liner models, there is no reciprocal communication involved with the video use.

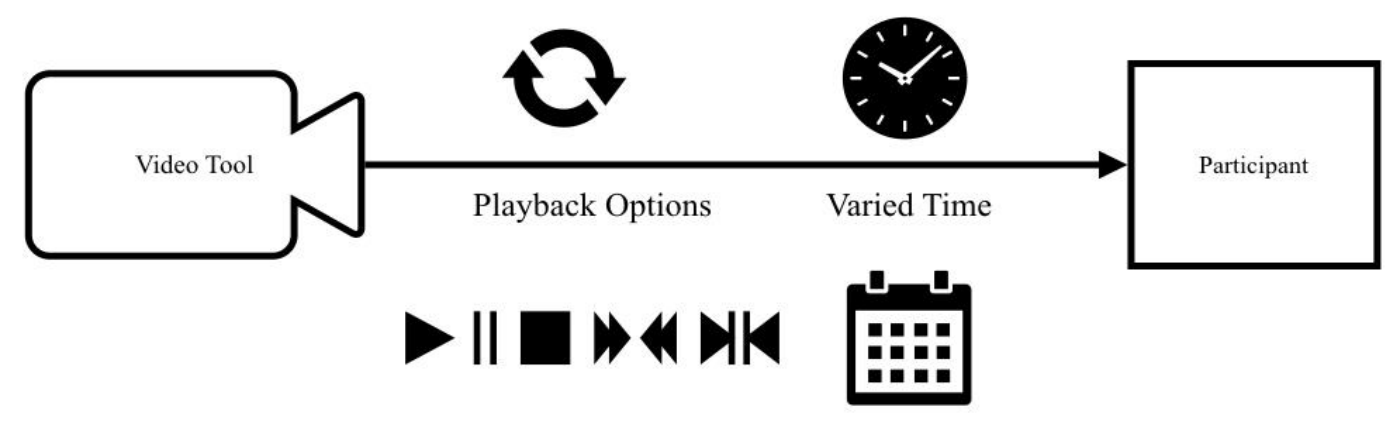

Figure 4. Asynchronous Linear Model

\subsection{Asynchronous Interactive Model}

This model is an active role use, see Figure 5. The asynchronous model allows for a back-and-forth between teachers and students, and it is not reliant upon a specific schedule. It also gives students who may have troubles being active in a synchronous lesson time to process the information and respond when they are ready. Tools such as FlipGrid assist and promote in these kinds of interactions. As Shahronki (2018) noted concerning a "the combination of appropriate videos, effective questions, and interactivity types can potentially result in the development of students' creative and critical thinking skills, and engaging learning experience" (Shahrokni, 2018, p. 113). 


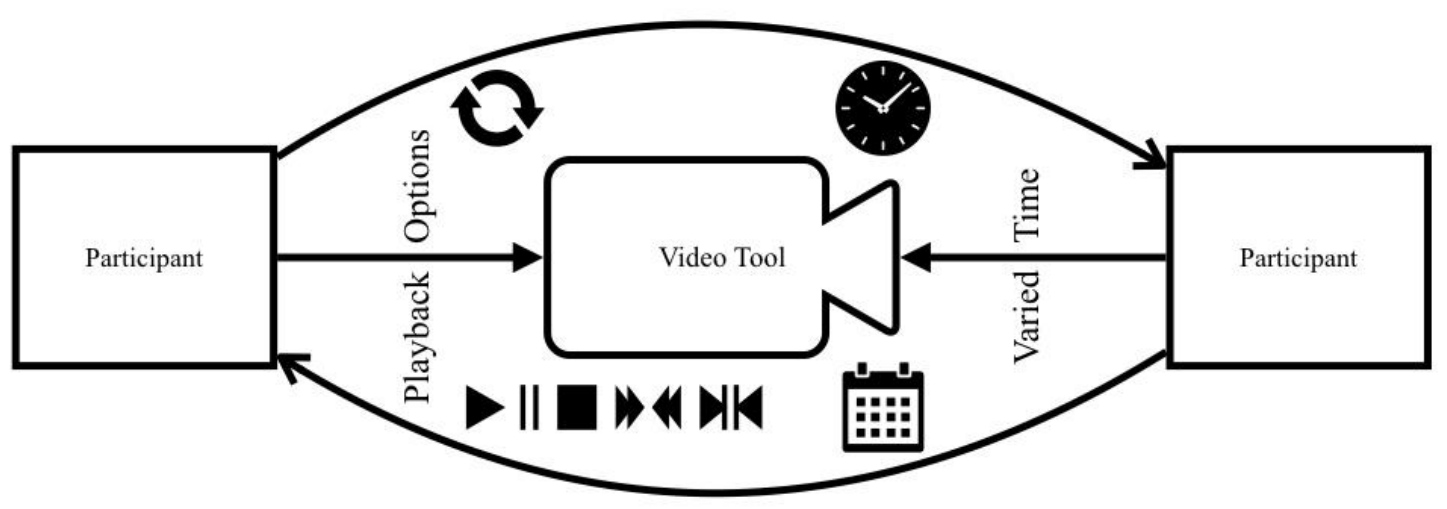

Figure 5. Asynchronous Interactive Model

\subsection{Asynchronous Group Interactive Model}

This model is an active role use, see Figure 6. This is an augmentation of the Asynchronous Interactive Model. Since the participants are not dependent on time constraints, users can comment or respond using video at any time. This model reduces the problem that sometimes arises with the Synchronous Group Interactive Model in that all members have a chance to speak on video. Group interaction with an asynchronous ensures that all participants have an equal opportunity for participation.

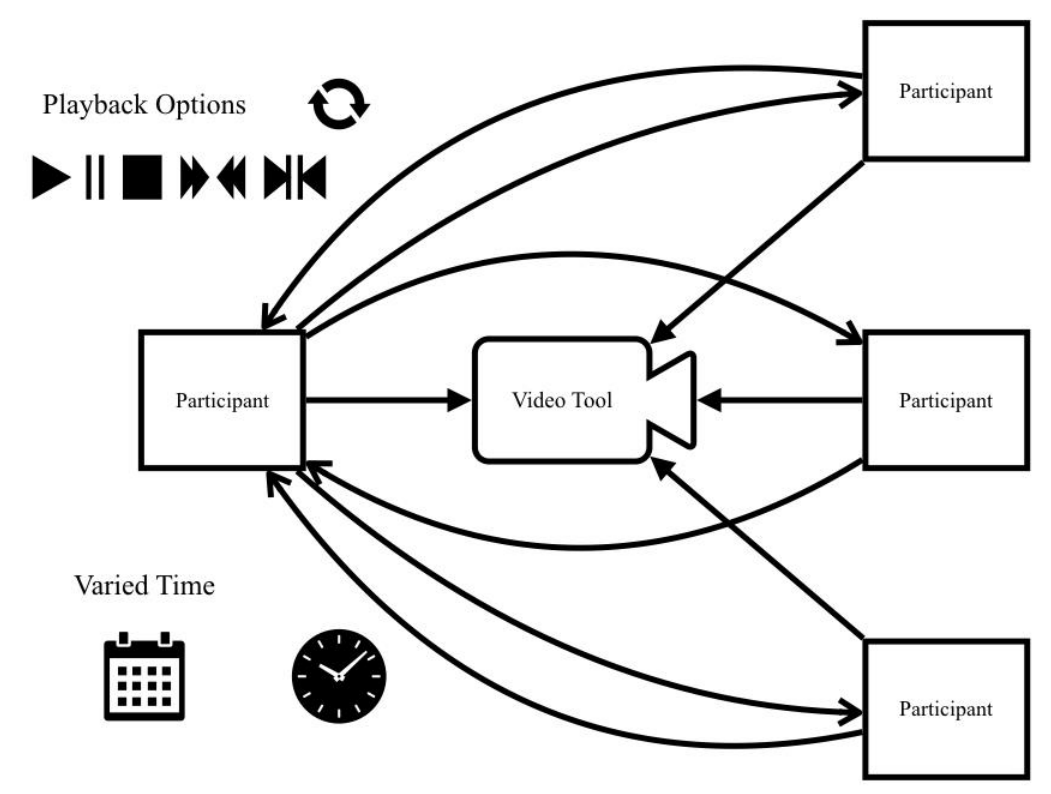

Figure 6. Asynchronous Group Interactive Model

\section{Combining the Video Attributes with the Video Communication Models}

The following graph represents the combination of use categories, video use communication 
models, and possible SAMR level.

\begin{tabular}{|c|c|c|c|c|c|}
\hline & $\begin{array}{c}\text { Video } \\
\text { Consumption }\end{array}$ & $\begin{array}{c}\text { Video } \\
\text { Interaction }\end{array}$ & $\begin{array}{c}\text { Video } \\
\text { Creation }\end{array}$ & Participant's Role & SAMR \\
\hline Synchronous Linear & $\checkmark$ & & & Passive & S \\
\hline Synchronous Interactive & $\checkmark$ & $\checkmark$ & & Active & SA \\
\hline $\begin{array}{c}\text { Synchronous Group } \\
\text { Interactive }\end{array}$ & $\checkmark$ & $\checkmark$ & & Active/Passive & SA \\
\hline Asynchronous Linear & $\checkmark$ & $\checkmark$ & $\mathfrak{J}^{*}$ & Active/Passive & SAM \\
\hline Asynchronous Interactive & $\checkmark$ & $\checkmark$ & $\checkmark$ & Active & AMR \\
\hline $\begin{array}{c}\text { Asynchronous Group } \\
\text { Interactive }\end{array}$ & $\checkmark$ & $\checkmark$ & $\checkmark$ & Active & AMR \\
\hline
\end{tabular}

Figure 7. Video Use Attributes + Communication Model Chart

\section{Video Implementation and the Digital Divide}

The following graph represents the combination of use categories, video use communication models, and possible SAMR level. Since there is increased access to the internet around the world, teachers in different countries can network and learn from each other using professional learning networks. With a simple Internet search, it is easy to find many different video tools and pedagogical suggestions that have support from bloggers, tech companies, and industry experts. Lesson plans and technology conferences show off the next new and exciting tech. And some will apply the theory presented in this paper to design more lessons. However, many of those tools are not easy for teachers to implement or access due to the barrier of entry related to cost or restrictive use by schools. Those who are connected to a district or have access to school budget are more likely to adopt these tools and even with that access approval for the instrument may be denied. It is essential to be flexible and advocate for the tool that is most affordable, easy to use, and reproducible. This difficulty in technology access is called the digital divide (2002).

The goal is not to hinder teachers from using video because of their possible inaccessibility to a particular tool. But to encourage teachers to be aware of the different pricing models, so there are no surprises when trying to implement an idea regarding video implementation. It is also to advocate for instructors and institutions to choose the free model as it is easier to duplicate and is more accessible to learners and is more portable for teachers who change jobs or work in areas that have different tools. The cost structure models outlined below are to help assess the video tools to find one that is both legally and financially viable for a particular situation. There are three tiers of cost structure video in the class, the pay model, the freemium model, and free model. 


\section{Macrothink}

1. The Pay Model: Are merely tools that must be purchased to use, there is no free version even if discounts for education are offered. Some of these services include complex technology hardware services that need to be set up before implementation. Outside trainers and other training may also need to happen depending on an instructor or a school's technology awareness. Pay models are harder to replicate or move to different situations since there is no freemium or free version.

2. The Freemium Model - The second model is the freemium model. These tools have a tier in their business model to include offering their service for free. It is possible to use this kind of tool effectively without upgrading to the paid model in some situations. The freemium model's free version usually has restricted offerings such as a limit of participants and time, but it varies according to the tool and the ultimate goal of the organization. Some of the attractive attributes of some of these tools are only available if upgrading to a paid account This model includes free software and solutions that only work on one operating system like Mac OS, Microsoft Windows since the purchase of the specific machine is necessary for access. If the free version is effective in implementation, then it is easier to replicate for other teachers and move with the instructor.

3. The Free Model - The final model is the free model. These are the free tools that are available on any device. Many times, these tools are also used outside of educational situations. This means that the barrier of technology skills needed is usually lower since peer support for these tools makes it easy for teachers to implement in classrooms no matter the budget. These tools are more accessible to replicate across different classes and can usually move with the instructor.

\section{Country and Cultural Considerations}

Note, not all countries have the same laws and internet access. Some tools are limited or not available in some countries. China and Russia have either limited or no access to services such as YouTube. The use categories and video use communication models developed in this paper were created with this in mind. Instructors can use the attributes of the models to see how they align with the video tools available to them and they can make better decisions for their classes.

\section{Conclusion}

As newer tools are developed the opportunity and ability for two-way interactive communication using video in the classroom is now possible. Different video implementation styles can be realized by more instructors from many different demographic backgrounds based on their location and available tools. By understanding the intersection between Video use Attributes and Video Use Communication Models (as developed in this paper), instructors can better understand the "what" and "why" of using video for their classes. Combining the 
understanding of the video tool pricing models and the video use communication models; will help align a video implementation to a teacher's pedagogical practice and their logistical situation more efficiently. As more and more teachers implement the different aspects of video integration communication cycles, more research can be done to further measure the effectiveness of video use for second language learning.

\section{Acknowledgement}

This work was supported by Hankuk University of Foreign Studies Research Fund of 2018

\section{References}

Bakar, N. A., Latiff, H., \& Hamat, A. (2013). Enhancing ESL learners speaking skills through asynchronous online discussion forum. Asian Social Science, 9, 224. https://doi.org/10.5539/ass.v9n9p224

Basal, A. (2015). The implementation of a flipped classroom in foreign language teaching. Turkish Online Journal of Distance Education. Retrieved from https://files.eric.ed.gov/fulltext/EJ1092800.pdf

Blonskyte, M. (2014). Case Study of the Use of Video Material in an English Classroom. Studies About Languages, O(25). https://doi.org/10.5755/j01.sal.0.25.8341

DeMaria, S., \& Fuhrman, C. (2011). English Language Arts-That's a Wrap! Telling Stories with Video. Learning and Leading with Technology.

Gan, B., Menkhoff, T., \& Smith, R. (2015). Enhancing students' learning process through interactive digital media: New opportunities for collaborative learning. Computers in Human Behavior, 51, 652-663. https://doi.org/10.1016/j.chb.2014.12.048

Hamilton, C. (2014). Communicating for Results: A Guide for Business and the Professions International Edition (10th ed.). Cengage Learning.

(2002). The New Dictionary of Cultural Literacy: What Every American Needs to Know digital divide. In E. D. Hirsch, Jr., J. F. Kett, \& J. Trefil. Boston: Houghton Mifflin. Retrieved from

http://sproxy.hufs.ac.kr/b41f8ad/_Lib_Proxy_Url/link.galegroup.com/apps/doc/A177459557/ ITOF?u=keris165\&sid=ITOF $\&$ xid=f9327af6

Kumar, V., \& Sharma, D. (2016). Creating Collaborative and Convenient Learning Environment Using Cloud-Based Moodle LMS. International Journal of Web-Based Learning and Teaching Technologies, 11(1), 35-50. https://doi.org/10.4018/ijwltt.2016010103

Muslem, A., Mustafa, F., \& Usman..., B. (2017). The Application of Video Clips with Small Group and Individual Activities to Improve Young Learners' Speaking Performance. Teaching English with ... 
http://cejsh.icm.edu.pl/cejsh/element/bwmeta1.element.desklight-3d8d23d7-a1dc-4905-97699dd44eb64787/c/ARTICLE2.pdf

Puentedura, R. R. (2013a). SAMR: Moving from enhancement to transformation (Presentation Slides). Retrieved from http://www.hippasus.com/rrpweblog/archives/2013/05/29/SAMREnhancementToTransformat ion.pdf

Puentedura, R. (2013b). SAMR and TPCK: Intro to advanced practice (Presentation Slides). Retrieved from http://hippasus.com/resources/sweden2010/SAMR_TPCK_IntroToAdvancedPractice.pdf

Ripton, J. T., \& Scott, P. (2016). Five Ways Teachers Can Use Video Chat in the Classroom EdSurge. Retrieved from https://www.edsurge.com/news/2016-06-23-five-ways-teachers-can-use-video-chat-in-the-cla ssroom

(2017). Ruben Puentedura on Applying the SAMR Model [Video file]. Retrieved from https://www.commonsense.org/education/videos/ruben-puentedura-on-applying-the-samr-mo del

Schramm, W. (1971). The process and effects of mass communication (Revised edition; Second edition. ed.). Urbana: University of Illinois Press.

Shahrokni, S. A. (2018). PLAYPOSIT: USING INTERACTIVE VIDEOS IN LANGUAGE EDUCATION (App Review). Teaching English with Technology, 18(1), 105-115. Retrieved from

http://yadda.icm.edu.pl/yadda/element/bwmeta1.element.desklight-eef8905e-ff62-46e8-b0289d3dd43bfa3b/c/ARTICLE7.pdf

Williams, R. T., \& Lutes, P. (2008). Using video in the ESL classroom. 高松大学紀要, 48(1), 13. Retrieved from http://www.takamatsu-u.ac.jp/library/06_gakunaisyupan/kiyo/no48/001-013_williams.pdf

Yang, L. (2014). Examining the mediational means in collaborative writing: Case studies of undergraduate ESL students in business courses. Journal of Second Language Writing, 23, 74-89. https://doi.org/10.1016/j.jslw.2014.01.003

Yousef, A. M. F., Chatti, M. A., \& Schroeder, U. (2014). Video-based learning: a critical analysis of the research published in 2003-2013 and future visions. Retrieved from https://pdfs.semanticscholar.org/1b1c/057c36ec34581959b9e4910fc147611c776f.pdf

Yu, L.-T. (2018). Native English-Speaking Teachers' Perspectives on Using Videoconferencing in Learning English by Taiwanese Elementary-School Students. JALT CALL Journal, 14(1), 61-76. Retrieved from https://files.eric.ed.gov/fulltext/EJ1177329.pdf 


\section{Copyright Disclaimer}

Copyright for this article is retained by the author(s), with first publication rights granted to the journal.

This is an open-access article distributed under the terms and conditions of the Creative Commons Attribution license (http://creativecommons.org/licenses/by/3.0/). 